\title{
Supplementary material for : A new approach for simulating the paleo evolution of the Northern Hemisphere ice sheets
}

R. Banderas ${ }^{1,2}$, J. Alvarez-Solas ${ }^{1,2}$, A. Robinson ${ }^{1,2}$, and M. Montoya ${ }^{1,2}$

${ }^{1}$ Universidad Complutense de Madrid (UCM)

${ }^{2}$ Instituto de Geociencias (UCM-CSIC)

Correspondence to: R. Banderas (banderas.ruben@ fis.ucm.es)

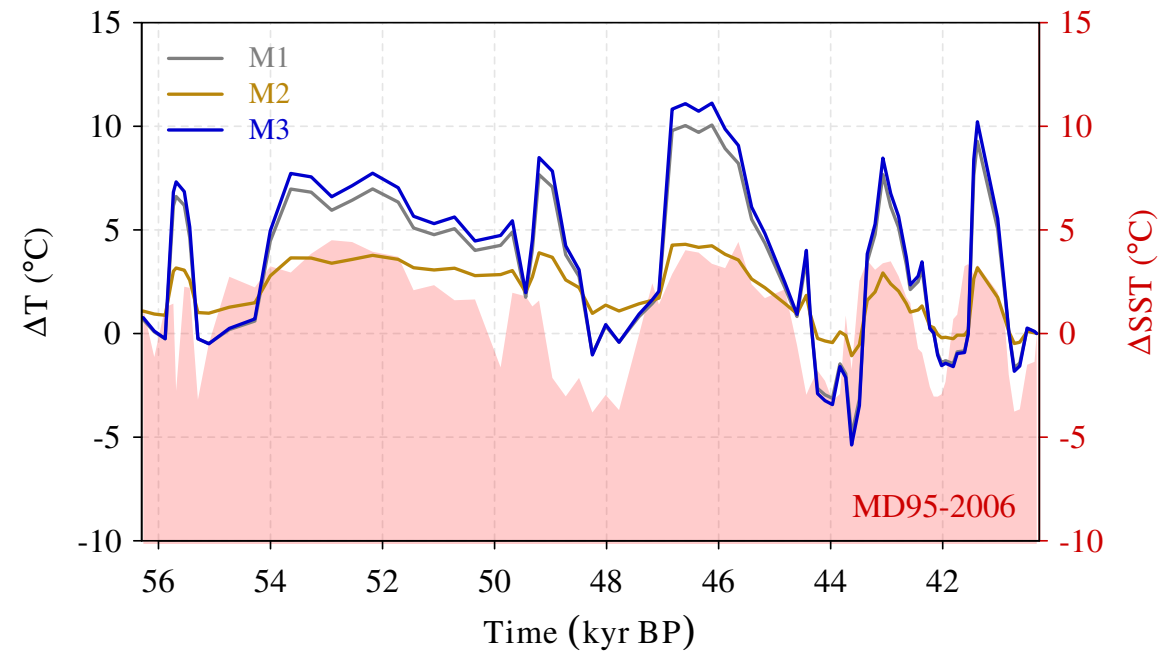

Figure S1. Temporal evolution of surface temperature anomalies $\left({ }^{\circ} \mathrm{C}\right.$ ) relative to present day obtained under the M1 (gray), M2 (gold) and M3 (blue) scenarios (solid curves) as compared to the SST temperature reconstruction (red shaded area) of sediment core MD95-2006 $\left(57.03^{\circ} \mathrm{N}, 10.06^{\circ} \mathrm{W}\right.$; Dickson et al., 2008). 

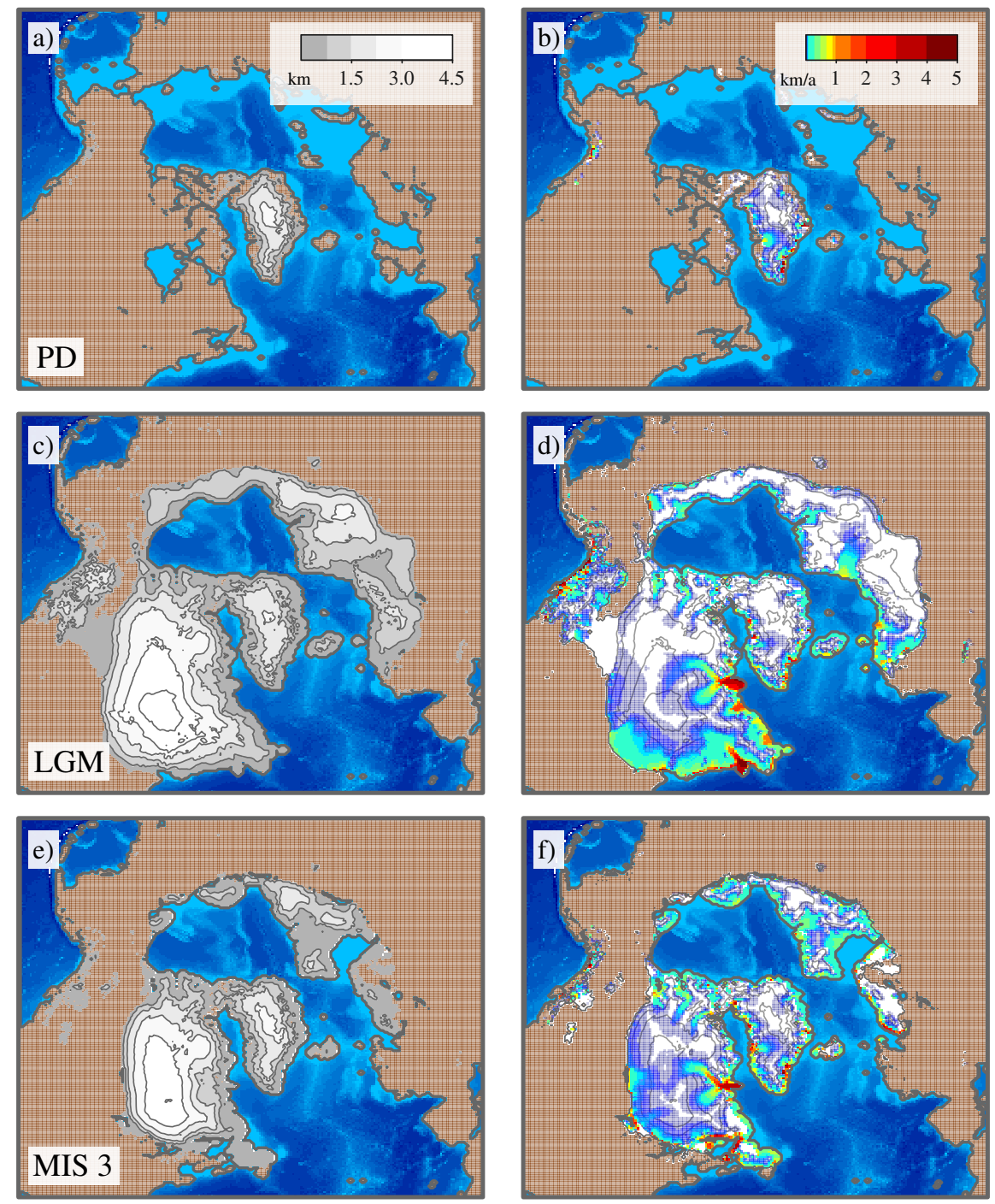

Figure S2. NH ice-sheet configurations at different stages of the last glacial-interglacial period as simulated under M1: a) present-day ice thickness ( $\mathrm{km}$ ) and b) present-day ice velocities $\left(\mathrm{km} \mathrm{a}^{-1}\right)$. Panels $\left.\left.\mathbf{c}\right)-\mathbf{d}\right)$ and e)-f) show the same information as a)-b) for the LGM and MIS3 stages, respectively. 

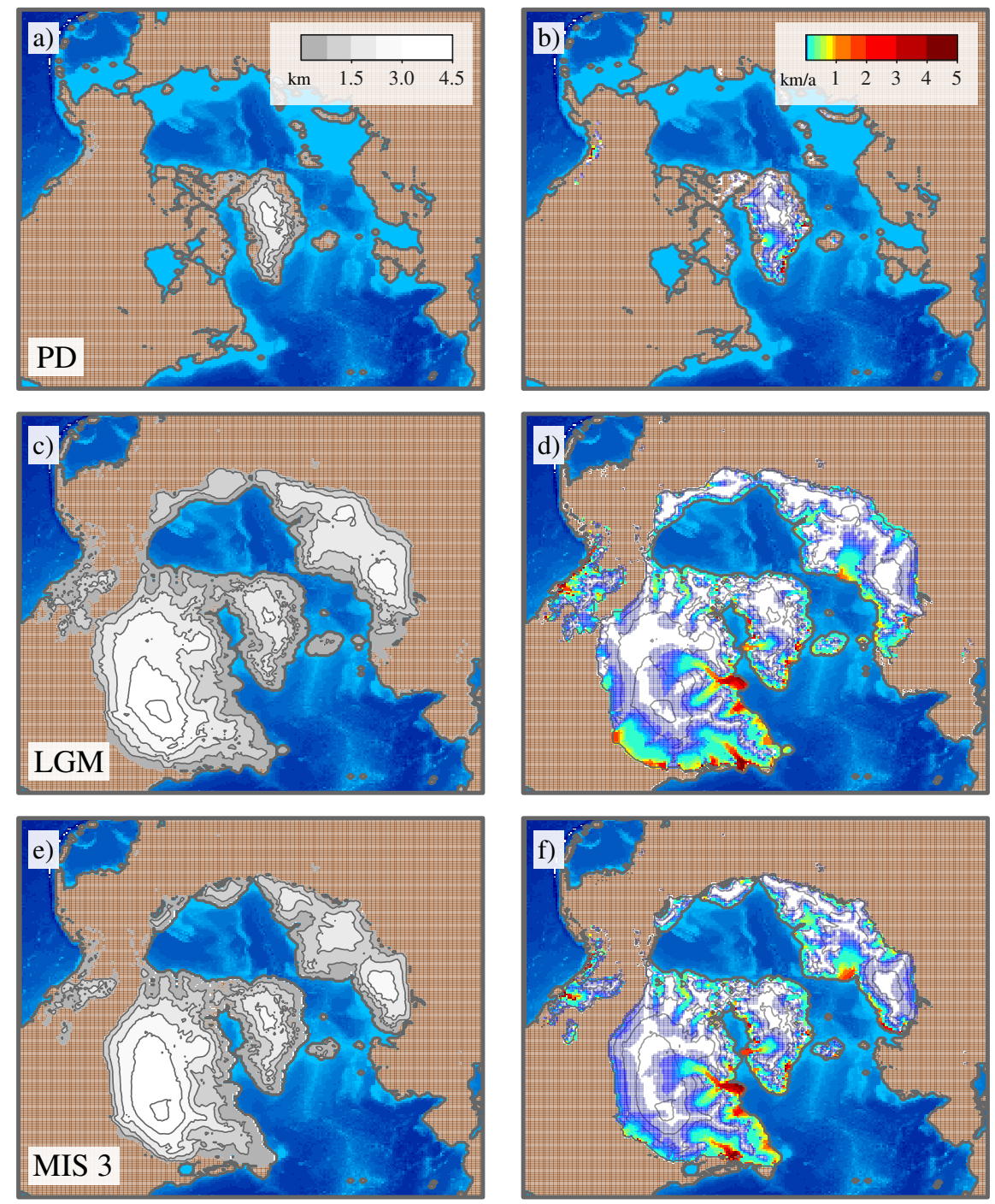

Figure S3. NH ice-sheet configurations at different stages of the last glacial-interglacial period as simulated under M2: a) present-day ice thickness ( $\mathrm{km}$ ) and b) present-day ice velocities ( $\mathrm{km} \mathrm{a}^{-1}$ ). Panels $\left.\left.\mathbf{c}\right)-\mathbf{d}\right)$ and $\left.\left.\mathbf{e}\right)-\mathbf{f}\right)$ show the same information as a)-b) for the LGM and MIS3 stages, respectively. 


\section{References}

Dickson, A. J., Austin, W. E., Hall, I. R., Maslin, M. A., and Kucera, M.: Centennial-scale evolution of Dansgaard-Oeschger events in sediment core MD95-2006, doi:10.1594/PANGAEA.832405, https://doi.pangaea.de/10.1594/PANGAEA.832405, supplement to: Dickson, Alexander J; Austin, William EN; Hall, Ian R; Maslin, Mark A; Kucera, Michal (2008): Centennial-scale evolution of Dansgaard-Oeschger events in the northeast Atlantic Ocean between 39.5 and 56.5 ka B.P. Paleoceanography, 23(3), PA3206, doi:10.1029/2008PA001595, 2008. 